\title{
Myths About Cardiovascular Diseases
}

\author{
Ruy Laurenti, Cassia Maria Buchalla
}

São Paulo, SP - Brazil

This study aims to present the myths about cardiovascular diseases, particularly those about ischemic heart disease.

Among the many widespread false conceptions about cardiovascular diseases, we can cite the following: ischemic heart disease prevails among rich people, it affects males almost exclusively, and it does not constitute a public health problem in developing countries. These ideas, on which our study is based, have been discussed by Martin ${ }^{1}$, who is responsible for the area of cardiovascular diseases at the World Health Organization.

We tried to present data that highlight the real situation of this group of diseases in our country and, therefore, to destroy false myths.

A great amount of scientific information reaches the public via the lay press that rapidly popularizes medical terms, practices, and behaviors. The influence of the lay press is great and especially well explored in regard to concepts and novelties in the area of health. Print and other communication media should be used more effectively by public health agencies because an interested public thirsty for health information exists.

Even though the findings of numerous epidemiological, clinical, and anatomicopathological studies, stressing the most varied characteristics of cardiovascular diseases, have been published in recent decades, a few false conceptions and notions persist about cardiovascular diseases, mainly about ischemic heart disease and cerebrovascular diseases, also generically known as cerebral stroke.

These false notions were analyzed in a synthetic but interesting and didactic manner by Martin ${ }^{1}$, who is responsible for the area of cardiovascular diseases at the World Health Organization, in a study titled "To end the myths about heart diseases." The author emphasizes that to prevent heart diseases, public health initiatives should be fomented, which can only be achieved with true notions gui-

Faculdade de Saúde Pública da Universidade de São Paulo

Mailing address: Ruy Laurenti - Rua Edmundo Scanapicco, 102 - 05516-070 São Paulo, SP, Brazil

English version by Stela Maris C. Gandour ding preventive attitudes. The author begins her article as follows: "Mistaken concepts about cardiovascular diseases - heart attacks, cerebral strokes, and hypertension have persisted for years, resulting in myths. Most of these myths were based on concrete observations in the initial phase of the current world epidemic, and they are deeply rooted in the minds of those responsible for health, professional, and public policies. As these mistaken concepts reflect negatively on resources offered and on prevention and control measures for cardiovascular diseases, we need to definitively eliminate them".

These points are interesting and pertinent because in professional activities, either teaching or clinical, mention of mistaken concepts about cardiovascular diseases by health professionals, including physicians, is frequent. The author of the previously cited article presents 6 myths in regard to cardiovascular diseases, commenting on each of them and stating that we need to eliminate them. Because of the importance and current nature of this topic, we found it interesting to compare that study to the existing reality in Brazil. The author agreed with the use of her idea as a base for our study with data from our country. Therefore, our study aims to discuss the myths related to cardiovascular diseases prevailing in Brazil.

\section{Myth I: cardiovascular diseases are problems of developed countries}

Martin ${ }^{1}$ draws attention to the fact that cardiovascular diseases cause approximately 15 million deaths per year around the world. This number corresponds to $30 \%$ of the total of deaths, and, of those deaths resulting from cardiovascular diseases, two thirds occur in developing countries. These countries have a number of deaths caused by cardiovascular diseases 2 times greater than that of developed countries. Analyzing the 2 most frequent causes of death in the group of cardiovascular diseases, we note that although those caused by cerebral stroke occur twice as often in developing countries than in developed countries, deaths due to heart attacks occur in equal numbers.

Approximately 35 years ago, an investigation ${ }^{2}$ on the mortality of adults from 15 to 74 years of age was carried out 
in 12 cities, one of them in the United States (San Francisco), another in England (Bristol), and the remaining 10 in Latin America. This study analyzed in a standardized way all cases of death in an age group through interviews with physicians, hospitals, clinics, and with people involved with the cases, as well as with family members. This methodology enabled correction of data, and, therefore, most reliable information was obtained.

In this study ${ }^{2}$, the 2 cities in developed countries (Bristol and San Francisco) were compared with the 10 Latin American cities, including São Paulo and Ribeirão Preto. Thirty-five years ago, mortality due to ischemic heart disease was greater in the 2 Anglo-Saxon cities, mainly among males. However, some Latin American cities already had high mortality rates for this group of diseases. At that time, among females, the rates were very similar in almost all cities.

In regard to cerebral stroke, mortality in several Latin American cities overcame that in the 2 cities in developed countries, for males and females, and São Paulo and Ribeirão Preto had the highest rates. In regard to hypertensive heart disease, the mortality rate was clearly higher in most Latin American cities, for both sexes (Table I) ${ }^{2}$.

Therefore, for 35 years, this study ${ }^{2}$ has shown that cardiovascular diseases are not solely the prerogative of the areas considered more developed or richer.

In Brazil, cardiovascular diseases are the most important causes of death (27.5\% in 1994), followed by external causes $(12.1 \%)$, and neoplasias $(10.8 \%)$. Infectious and parasitic diseases, historically related to poorness, appear in sixth position responding to only $4.7 \%$ of the total of deaths. And in the global social and economic context, Brazil is considered a developing country. On the other hand, our country has 2 regions considered "more developed" or "richer" (Southern and Southeastern regions) and 2 "less developed" or "less rich" regions (Northern and Northeastern regions). According to table II, cardiovascular diseases are the major causes of death even in the latter 2 regions.

In his study ${ }^{3}$, Husten predicts a world scenario for the

\begin{tabular}{|c|c|c|c|c|c|c|}
\hline \multicolumn{7}{|c|}{$\begin{array}{l}\text { Table I - Mortality rates due to } 3 \text { types of cardiovascular diseases, } \\
\text { according to sex, in the age bracket from } 15 \text { to } 74 \text { years, in } 12 \\
\text { cities, from } 1962 \text { to } 1964 \text { (per } 100,000 \text { inhabitants) }\end{array}$} \\
\hline & \multicolumn{2}{|c|}{ Stroke } & \multicolumn{2}{|c|}{$\begin{array}{c}\text { Ischemic } \\
\text { heart disease }\end{array}$} & \multicolumn{2}{|c|}{ Hipert. } \\
\hline Cities & M & $\mathrm{F}$ & $\mathrm{M}$ & $\mathrm{F}$ & M & $\mathrm{F}$ \\
\hline Bogota & 50.8 & 57.4 & 78.0 & 46.4 & 23.2 & 33.2 \\
\hline Bristol & 56.1 & 43.1 & 162.8 & 46.4 & 12.5 & 10.1 \\
\hline Cali & 41.9 & 45.0 & 54.7 & 20.5 & 32.6 & 30.8 \\
\hline Caracas & 44.9 & 33.1 & 98.5 & 38.2 & 12.8 & 15.8 \\
\hline Guatemala & 28.3 & 32.9 & 26.1 & 10.4 & 6.7 & 9.3 \\
\hline La Plata & 65.8 & 36.8 & 93.8 & 27.1 & 23.3 & 18.3 \\
\hline Lima & 66.4 & 39.4 & 60.6 & 22.4 & 26.4 & 21.1 \\
\hline Mexico City & 35.5 & 43.3 & 69.3 & 26.0 & 11.1 & 11.6 \\
\hline Ribeirão Preto & 91.8 & 69.1 & 53.0 & 31.9 & 44.1 & 24.8 \\
\hline San Francisco & 38.5 & 37.1 & 191.2 & 56.0 & 11.8 & 6.4 \\
\hline Santiago & 73.5 & 60.4 & 77.4 & 36.7 & 12.1 & 13.5 \\
\hline São Paulo & 78.8 & 61.8 & 95.0 & 40.6 & 28.0 & 35.0 \\
\hline
\end{tabular}

\begin{tabular}{|c|c|c|c|c|c|c|}
\hline \multicolumn{7}{|c|}{$\begin{array}{l}\text { Table II - Proportional mortality (\%) due to cardiovascular } \\
\text { diseases (CVD), infectious and parasitic diseases (IPD) and } \\
\text { external causes (EC) according to the Brazilian regions, } 1994\end{array}$} \\
\hline \multirow[b]{2}{*}{ Regions } & \multicolumn{2}{|c|}{ CVD } & \multicolumn{2}{|c|}{ IPD } & \multicolumn{2}{|c|}{ EC } \\
\hline & $\%$ & Position & $\%$ & Position & $\%$ & Position \\
\hline North & 17.8 & $1^{\mathrm{a}}$ & 7.0 & $4^{\mathrm{a}}$ & 13.9 & $2^{\mathrm{a}}$ \\
\hline Northeast & 19.5 & $1^{\mathrm{a}}$ & 6.3 & $3^{\mathrm{a}}$ & 9.6 & $2^{\mathrm{a}}$ \\
\hline Southeast & 30.6 & $1^{\mathrm{a}}$ & 4.1 & $7^{\mathrm{a}}$ & 12.5 & $2^{\mathrm{a}}$ \\
\hline South & 32.6 & $1^{a}$ & 3.2 & $7^{\mathrm{a}}$ & 11.8 & $3^{\mathrm{a}}$ \\
\hline West Central & 27.1 & $1^{\mathrm{a}}$ & 6.4 & $5^{\mathrm{a}}$ & 17.6 & $2^{\mathrm{a}}$ \\
\hline Brazil & 27.5 & $1^{\mathrm{a}}$ & 4.7 & $6^{\mathrm{a}}$ & 12.1 & $2^{\mathrm{a}}$ \\
\hline $\begin{array}{l}\text { Source: Morta } \\
\text { nal de Saúde. }\end{array}$ & lade & Brasil, 199 & Bras & : CENEP & undaç & ão Nacio- \\
\hline
\end{tabular}

next 2 decades with an epidemic of cardiovascular diseases in less developed countries. According to him, the current trend results from an increase in the risk factors for cardiovascular diseases due to better economic conditions and increase in life expectancy. He also considers the unhealthy lifestyle of populations as one of the causes for an increase in the incidence of cardiovascular diseases.

Other data could be presented for Brazil and also for other countries or regions of the world showing that cardiovascular diseases constitute a health problem not only for developed countries.

\section{Myth II: cardiovascular diseases are a health problem of rich people}

"In all societies, some people rapidly adopt changes in life style while others take longer to do so. At the beginning of the heart disease epidemic, only those better-off people in developing countries adopted the new life styles consisting of, among other things, consuming food rich in fat and calories, having a car, and smoking. Now that these goods are consumed by the masses, this unhealthy behavior is widespread among all social classes. Currently, rich people, mainly those in urban areas, have better access to health information regarding risk factors diffused by the communication media and may change their behavior to a healthier life style (nutritious food, physical activity, smoking cessation). This is the group that first adopts changes in life style, while the underprivileged people of the cities and rural communities stay out of this trend because they have less access to information and lack time and money to acquire healthier food and to exercise, which would keep them in shape. The result is a hazardous life style and an increase in risk factors" '.

Martin's statements ${ }^{1}$ cited above show in a very simple and direct manner the issue of rich and poor people in regard to cardiovascular diseases. The author also comments on the myth of heart diseases being a problem of rich people: "Also in industrialized countries, where the epidemic began some decades earlier than in the developing world, cardiovascular diseases are currently more common in the relatively poor sectors. When the world epidemic of heart disease reaches its maximum levels, the most affected 
will be the poorest countries and the poorest sectors of society".

Clinicians, in general, and cardiologists, in particular, know very well the "social and economic typology" of the patients with cardiovascular diseases, especially in public hospitals of our country. This experience leads to, or should lead to, destruction of the myth that this group of diseases is a problem of rich people.

Among the various epidemiological studies showing the prevalence of cardiovascular diseases or their risk factors in the population, we found the study by Achutti ${ }^{4}$ in the adult population of 4 areas in the city of Porto Alegre to be important. His results show that the lower the educational level, the higher the exposure to risk factors. These results led Costa e Silva ${ }^{5}$ to comment: "According to this study, the lower the educational level, the higher the exposure to risk factors, which shows the perverse tendency of a higher risk of illness and mortality due to potentially preventable diseases in the population with a lower educational level and, possibly, with a lower income, and, therefore, with limited access to the benefits of prevention and treatment of these diseases."

Table III clearly shows the prevalence of 5 risk factors (hypertension, alcohol use, obesity, smoking, and a sedentary life style) according to educational level ${ }^{4}$. Therefore, an inverse relation exists between the educational level, which in reality translates to the social and economic condition of an individual, and the prevalence of risk factors for cardiovascular diseases. The study by Achutti ${ }^{4}$ clearly establishes the relation between poverty and the risk for cardiovascular diseases.

Still considering the issue of cardiovascular diseases and "the poor versus the rich", Lopes ${ }^{6}$ analyzed the racial factor and hypertension, clearly showing that several international and Brazilian studies consistently indicate that prevalence of hypertension is higher among black people than among white people. The author discusses the possible interactions between genetic and environmental factors, which contribute to the greater risk of hypertension among black people, in particular the psychosocial factors. In Brazil, like in other countries of the Americas, such as the United States, a strong population contingent of black people exists, most of whom may be considered as "poor". Therefore, hypertension as a strong risk factor for ischemic heart disease and cerebral stroke partially explains the contribu-

\begin{tabular}{|c|c|c|c|c|c|}
\hline \multicolumn{6}{|c|}{$\begin{array}{l}\text { Table III - Prevalence (\%) of risk factors for cardiovascular disease } \\
\text { according to educational level in the city of Porto Alegre, Brazil, } 1997\end{array}$} \\
\hline Educational & Hypertension & $\begin{array}{l}\text { n Alcohol } \\
\text { use }\end{array}$ & Obesity & Smoking & $\begin{array}{l}\text { Sedentary } \\
\text { life style }\end{array}$ \\
\hline University & 6.6 & 9.8 & 10.0 & 46.0 & 74.7 \\
\hline High school & 8.0 & 18.2 & 18.0 & 47.0 & 79.1 \\
\hline Elementary & 19.9 & 18.1 & 31.0 & 55.0 & 85.3 \\
\hline Illiterate & 27.8 & 33.3 & 47.0 & 72.0 & 87.3 \\
\hline
\end{tabular}

tion of black people to the significant prevalence of cardiovascular diseases among "poor people".

$\mathrm{Chor}^{7}$ analyzed the cardiovascular risk profile among employees in a state bank and showed some interesting points, such as the higher frequency of some risk factors among those in a lower functional category and lower educational level.

It is clear that cardiovascular diseases are not a prerogative of rich people, on the contrary! Therefore, this myth is completely false!

\section{Myth III: cardiovascular diseases affect mainly males}

Martin ${ }^{1}$ stresses that even though ischemic heart disease is less common in premenopausal women than in men, in many parts of the world it is the most frequent cause of death in women, including those under 65 years of age. In regard to the topic, she states: "Heart disease, like its risk factors, varies a lot among different populations. According to a recent study by the World Health Organization about tendencies of cardiovascular diseases (MONICA project), the rates of heart attack in women aged from 35 to 64 years in Glasgow (Scotland) and Belfast (North Ireland) are higher than those in men from some regions of Southern Europe".

Table I clearly shows that cardiovascular diseases, particularly cerebral strokes and hypertensive heart disease, are not exclusive to males. In several cities studied, these 2 types of cardiovascular diseases had a higher mortality rate among females. The results from the study by Puffer and Griffith ${ }^{2}$ carried out more than 3 decades ago, like several others even older, justify the elimination of this myth, and they are supported by other more recent studies ${ }^{8,9}$.

Laurenti et $\mathrm{al}^{8}$, analyzing the epidemiological profile of male health in the Americas showed that, even though mortality due to cardiovascular diseases is higher in males, it is also significant among females. This was confirmed by Lotufo $^{9}$, and figure 1 shows the high mortality in females aged from 45 to 64 years, in some countries and Brazilian cities.

These data may be used to fight against myths I and III. In reality, the high female mortality due to ischemic heart disease is notable in 4 capitals of Brazilian states (São Paulo, Porto Alegre, Curitiba, and Rio de Janeiro) with rates higher than almost all developed countries chosen for comparison (fig. 1).

Clinical and epidemiological studies clearly show that this is a false myth. In reality, cardiovascular diseases are not exclusive male diseases.

\section{Myth IV: cardiovascular diseases are a pro- blem of elderly people}

This is a belief among the general public and health professionals. The frequency of cardiovascular diseases undoubtedly increases with age progression. Martin ${ }^{1}$ cites the industrialized countries, where one third of heart atta- 
cks and one fourth of cerebral strokes happen in people under 65 years old, while in developing countries, this situation is more marked. Reddy and Yusuf ${ }^{10}$ report that in less developed countries the high incidence of cardiovascular disease occurring before 65 years of age may be considered a result of the poor quality of medical care. We may add that a significant part of the population has difficulty in accessing any type of medical care.

Chor ${ }^{11}$ reported very well the existence of early mortality in Brazil, while Lotufo ${ }^{12}$ showed that the proportional mortality due to ischemic heart disease and cerebral stroke in the age bracket from 35 to 64 years in several regions of Brazil and developed countries is highly representative. Therefore, mortality due to ischemic heart disease reaches 39\% in England, 38\% in Finland, and in the Brazilian capitals it ranged from $21 \%$ (cities of Porto Alegre, Rio de Janeiro, and Curitiba) to $11 \%$ (city of Salvador) in the male sex. In regard to the female sex, this percentage is lower, sometimes reaching values above $15 \%$. Table IV shows the proportional mortality due to ischemic heart disease and cerebral stroke in males from 35 to 64 years of age. Table $\mathrm{V}$ shows the proportional mortality (\%) due to ischemic heart disease according to age groups and regions of the country. Therefore, $11.6 \%$ of the deaths due to cardiovascular diseases occur from 30 to 49 years of age, and $35.7 \%$ from 50 to 69 years of age. In all Brazilian regions, the incidence of deaths due to ischemic heart disease in the age bracket from 30 to 49 years is above $11 \%$ of all deaths, except for the Southern region $(9.9 \%)$.

Data reported confirm that cardiovascular diseases are not a prerogative of elderly people or individuals over 65 or 70 years of age. On the other hand, information in table IV also helps to eliminate myth I.

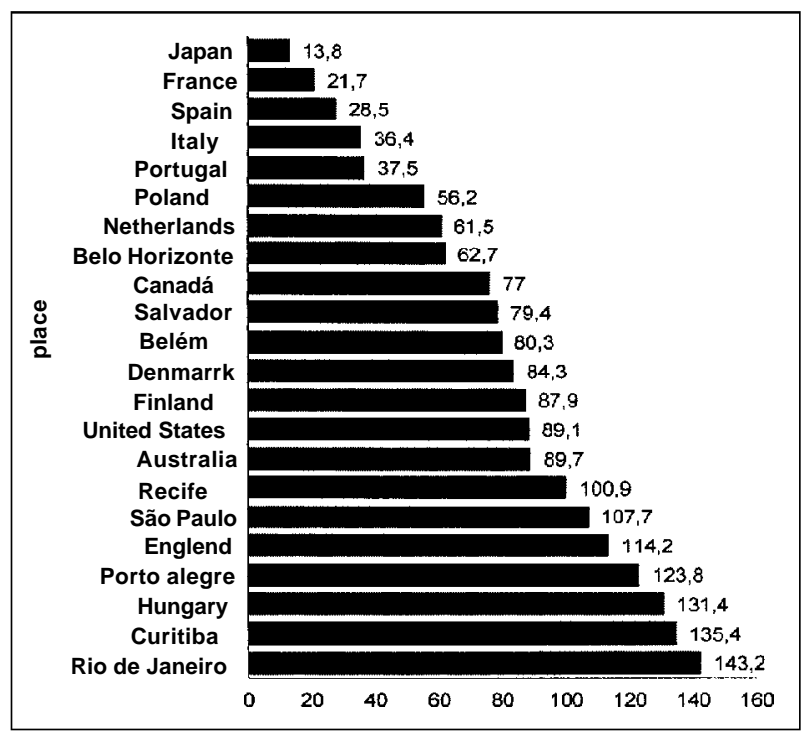

Fig. 1 -Ischemic heart disease mortality in womem between 45 and 64 years-old. (7 brazilian state capitals and 16 countries) 1984 to 1987 (ratio per 1000.000). Source: reference 9 .

\section{Myth V: cardiovascular diseases are not ame- nable to preventive action in the community}

In the United States, from the mid 60's on, a decline in mortality due to ischemic heart disease began to occur, persisting until today.

A little more than 1 decade after the beginning of this decline, the Conference on the Decline in Coronary Heart Diseases ${ }^{13}$ was held in Bethesda, MD, aiming to discuss with specialists of various fields this decline and, mainly, try to identify the possible factors accounting for this fact. At that time, in addition to the possible factors, such as the advance in medical and surgical therapeutics, a decrease in the prevalence of the major risk factors was evident, contributing to a decrease in the incidence of ischemic heart disease, which was reflected in mortality.

Several studies pointed to the hypothesis that the re-

\begin{tabular}{|c|c|c|}
\hline \multicolumn{3}{|c|}{$\begin{array}{c}\text { Table IV - Proportional mortality (\%) due to ischemic heart } \\
\text { disease (IHD) and cerebral stroke in } 14 \text { developed countries and } \\
\text { capitals of Brazilian states, in males aged from } 35 \text { to } 64 \text { years, in } \\
\text { the period from } 1984 \text { to } 1987 .\end{array}$} \\
\hline Countries and Brazilian capitals & $\operatorname{IHD}(\%)$ & Stroke $(\%)$ \\
\hline England & 39.0 & 6.0 \\
\hline Netherlands & 29.0 & 4.0 \\
\hline Australia & 32.0 & 5.0 \\
\hline Canada & 30.0 & 3.0 \\
\hline Finland & 38.0 & 6.0 \\
\hline USA & 27.0 & 4.0 \\
\hline Italy & 17.0 & 7.0 \\
\hline Denmark & 29.0 & 4.0 \\
\hline Japan & 6.0 & 12.0 \\
\hline Spain & 15.0 & 7.0 \\
\hline Hungary & 22.0 & 11.0 \\
\hline Porto Alegre & 21.0 & 10.0 \\
\hline Rio de Janeiro & 21.0 & 29.0 \\
\hline Poland & 19.0 & 5.0 \\
\hline France & 11.0 & 5.0 \\
\hline Curitiba & 21.0 & 15.0 \\
\hline Belém & 14.0 & 14.0 \\
\hline Portugal & 12.0 & 12.0 \\
\hline Belo Horizonte & 11.0 & 15.0 \\
\hline São Paulo & 18.0 & 12.0 \\
\hline Salvador & 11.0 & 12.0 \\
\hline Recife & 15.0 & 11.0 \\
\hline
\end{tabular}

\begin{tabular}{|c|c|c|c|c|}
\hline \multicolumn{5}{|c|}{$\begin{array}{l}\text { Table } \mathrm{V} \text { - Proportional mortality (\%) due to ischemic heart disease } \\
\text { according to some age brackets and Brazilian regions, } 1994 .\end{array}$} \\
\hline Ages & 30 to 49 & 50 to 69 & 70 and over & 30 and over \\
\hline Regions & $\%$ & $\%$ & $\%$ & $\%$ \\
\hline North & 12.9 & 35.1 & 46.7 & 94.7 \\
\hline Northeast & 11.4 & 33.4 & 50.7 & 95.5 \\
\hline Southeast & 11.8 & 36.2 & 49.4 & 97.4 \\
\hline South & 9.9 & 35.7 & 52.4 & 98.0 \\
\hline West Central & 14.1 & 37.6 & 43.3 & 95.0 \\
\hline Brazil & 11.6 & 35.7 & 49.7 & 97.0 \\
\hline
\end{tabular}


duction in mortality resulted from changes in the status of the risk factors in the population.

Scholars in the cardiology field (clinicians, pathologists, and epidemiologists) accept the fact that the results from the Framingham study ${ }^{14}$ accounted for the current knowledge about the risk factors for ischemic heart disease. Diffusion of this knowledge made the population adopt individual or collective, or both, measures to prevent ischemic heart disease. Such measures undoubtedly helped a lot to reduce mortality due to ischemic heart disease.

This decline in mortality has been observed in various countries and has been reported in our country as well for ischemic heart diseases and also for cerebral stroke ${ }^{15-18}$.

Changes in behavior in population segments, with a reduction in risk factors, undoubtedly favor the decrease in the incidence of ischemic heart diseases and cerebral stro$\mathrm{ke}$. This reduction reflects indirectly in a decrease in morbidity, and through secondary prevention it may directly decrease mortality. Therefore, myth $\mathrm{V}$ is not valid, ie, cardiovascular diseases are in fact amenable to preventive actions in the community.

Chor ${ }^{7}$ is very honest in reporting in her study that "cardiovascular diseases may be reduced". She states: "Efforts in prevention currently developed have a higher probability of delaying the onset of ischemic heart disease and cerebrovascular diseases than that of avoiding them. A reduction in their incidence rates would be achieved if a new generation developed with healthier habits and environment, from the beginning of their lives until adulthood. Control of the causes of atherosclerosis and of elevation of blood pressure, however, has benefits in regard to longevity and improvement in quality of life, being, therefore, justifiable in countries like Brazil, where, as already seen, mortality due to cardiovascular diseases affects a great number of young adults".

\section{Myth VI: cardiovascular diseases are no longer a problem of public health}

When commenting on this myth, Martin ${ }^{1}$ reports that, even though the incidence of cardiovascular diseases has been decreasing in industrialized countries, they will continue to be a predominantly public health problem. In addition, countries in Eastern Europe began to have an elevation in mortality due to this group of diseases. Estimates exist that these diseases will cause twice the number of deaths in developed countries in 2020 as compared with those in 1990.

Even though this sixth myth is discussed in Martin's study ${ }^{1}$, it does not seem to have the same strength as the others. To adapt it to our reality may be inappropriate, because it is not a belief widespread among us. On the contrary, this group of diseases is reported and discussed more and more as one of the major health problems in our country.

\section{Comments}

The possibility of primary and secondary prevention of cardiovascular diseases, in the individual and on the collective level, is an unquestionable fact. However, the myths presented, which are beliefs related to this group of diseases, act in a negative way and may reduce the effects of preventive programs. Therefore, the belief that heart disease is "a disease of elderly people" contributes to the young adopting a life style not adequate for prevention, mainly in regard to dietary habits. Studies have shown that healthy dietary habits should start in childhood.

The idea deeply rooted in the population that this group of diseases are more prevalent among males also contributes to women underestimating some specific symptoms, making an early diagnosis difficult.

The myth that cardiovascular disease is a "disease of rich people" spread with no scientific support. It may be explained by the limited access of poor people to more refined diagnoses and, mainly, the limited access to information and adoption of preventive behaviors. Habits such as smoking and excessive alcohol consumption are very prevalent among underprivileged people, a population group that resists adoption of preventive behaviors.

Even though alcohol consumption in moderate amounts has been associated with some degree of protection against cardiovascular diseases, studies have shown that constant ingestion of large amounts of alcohol increases the risk of death not only due to cardiovascular diseases, but also due to cancer and external causes. However, information regarding cardiovascular diseases is limited as to the benefits of alcoholic beverage consumption.

At the same time that some myths have been eliminated by the media, new beliefs have replaced them. This has been happening due to the great interest of the press in regard to health topics. In important weekly magazines, a section on health is routinely published with the results of current scientific studies. Usually, these magazines reproduce articles that have been recently published in international scientific journals. This way, with the article translated into an accessible language, the public is informed about some results before most physicians have the opportunity to read them directly in a medical journal. These articles are well received and are reproduced in numerous publications around the world, including in Brazil. However, even though these articles are published in mass communication media, only a part of the population, which is better informed, "receives" or effectively understands the information.

People with access to this avalanche of information start seeing certain dietary habits as politically correct. On the other hand, they frequently begin to doubt everything, even when individually instructed by physicians, because that which was initially good, may not be confirmed in subsequent studies.

An example of this variation is those articles recently published in lay magazines about certain foods, such as egg, margarine, and salt, and their relation to an increase in cholesterol levels. This food, until then excluded from a healthy diet, seems to be rehabilitated, being even indicated for people with no increase in cholesterol levels.

In recent decades, the lay press has undoubtedly contri- 
buted to the behavioral change in regard to recognized risk factors. We may cite the increasing number of people exercising, the proliferation of fitness centers, and changes in dietary habits. In regard to a certain social class, we consider that information provided by the media proved to be more useful than official programs directed at communities or even individual counseling provided by physicians. However, sometimes, this information contributes to the creation of new myths.
The population would benefit more if information about health could be better diffused by the media, which could use the known resources to make the information available to less privileged classes. Certainly these measures will be important in destroying deeply rooted myths, which are not true, and that certainly have contributed to making prevention of cardiovascular diseases at individual and collective levels difficult.

\section{References}

1. Martin, I. Acabar con los mitos sobre las cardiopatias. Salud Mundial 1998; 51: 6-7.

2. Puffer RR, Griffith GW. Caracteristicas de la mortalidad urbana. Organización Panamericana de la Salud. Publicación Cientifica 151. Washington, DC, 1968.

3. Husten, L. Global epidemic of cardio-vascular diseases predicted. Lancet 1998; 352: $1530-42$

4. Achutti, A. Cardiovascular diseases epidemiology in Brazil. Apresentação feita no " $13^{\text {rd }}$ World Congress of Cardiology". Rio de Janeiro, 1998.

5. Costa e Silva VL. Impacto do tabagismo em óbitos por infarto agudo do miocárdio, em mulheres de 30 a 59 anos no município do Rio de Janeiro. Tese de Doutorado, Escola Nacional de Saúde Pública - FIOCRUZ. Rio de Janeiro, 1999.

6. Lopes AA. Raça e hipertensão arterial. Hiperativo 1996; 3: 153-72.

7. Chor D. Perfil de risco cardiovascular de funcionários de banco estatal. Tese de Doutorado, Faculdade de Saúde Pública - USP. São Paulo, 1996.

8. Laurenti R, et al. O perfil epidemiológico da saúde masculina na Região das Américas: uma contribuição ao enfoque de gênero. Centro Colaborador da Organização Mundial da Saúde para a Classificação de Doenças em Português. Faculdade de Saúde Pública - USP, 1998.

9. Lotufo PA. Premature mortality from heart disease in Brazil. A comparison with other countries. Arq Bras Cardiol 1998; 70: 321-5.

10. Reddy KS, Yusuf S. Emerging epidemic of cardiovascular disease in developing countries. Circulation 1998; 97: 596-601.
11. Chor D. Doenças cardiovasculares. Comentários sobre a mortalidade precoce No Brasil. Arq Bras Cardiol 1995; 64: 15-19.

12. Lotufo PA. A mortalidade precoce por doenças crônicas nas capitais de Regiões metropolitanas do Brasil. Tese de Doutorado. Faculdade de Saúde Pública - USP, São Paulo, 1996.

13. Havlik RJ, Feinleib M. Proceedings on the conference on the decline in coronary heart disease mortality. Nat. Heart, Lung and Blood Institute. U.S. Dept. of Health, Education and Welfare. Editors, 1979 Nat. Institute of Health, NIH Publications $n^{\circ}$ 79-1610, May 1979.

14. Dawber TR. The Framingham study. The epidemiology of atherosclerotic disease Cambridge: Harvard University Press, 1980.

15. Lolio CA, Laurenti R (a). Evolução da mortalidade por doença isquêmica do coração no município de São Paulo, 1980 a 1981. Arq Bras Cardiol 1986; 46 : 153-6.

16. Lolio CA, Laurenti R (b). Tendências de mortalidade por doença cerebrovascular em adultos maiores de 20 anos de idade no município de São Paulo, 1950 a 1981. Rev Saúde Pública 1986; 20: 343-6.

17. Lotufo PA, Lolio CA (a). Tendência da mortalidade por doença isquêmica do coração no estado de São Paulo: 1970 à 1989. Arq Bras Cardiol 1993; 61: 149-53.

18. Lotufo PA, Lolio CA (b). Tendência da mortalidade por doença cerebrovascular no Estado de São Paulo: 1970 à 1979. Arq Neuropsiquiatria 1993; 51: 441-6. 